\title{
Expectations Vs. Reality: A Narrative Anecdotal Approach to Examining the Digital Tools Used to Engage Undergraduate Students During Pandemic
}

\author{
Mifrah Ahmad \\ Deakin University Melbourne Australia \\ Hesaam Kashi \\ Deakin University Melbourne Australia
}

Pandemic has transformed higher education expectations, but realistically, the challenges encountered during this transition are enormous. Despite much published work on the positive outcome of technological use, the sudden change profoundly impacted factors such as students' learning engagement and motivation, technological difficulties, feedback during live lectures, mental health, and the need to provide a 'realistic' experience. Therefore, this paper sheds light on the above factors through an educator's reflective and experiential learning (researcher and learner). The authors accumulated narrative, anecdotal records, and observations over ten months. The narrative records were noted and observed as an educator, who documented the learning experiences and relationships of how interactions and engagements occurred with students. Adapting foundational guidelines by (Beaty, 1986) for descriptive narrative records, a thematic analysis is achieved for themes and commonalities to emerge. Results are discussed through the interpretivism paradigm with the hermeneutic method to understand educators' experience throughout the anecdotal responses. Finally, criticizing and evaluating the digital tools used for undergraduate students is crucial to identifying the possible challenges and similarities.

Keywords: undergraduate students' engagement, digital tools, MS teams, challenges, experiential learning, interpretivism, online learning, distance

\section{INTRODUCTION}

Technology has been a prominent contribution to education. The use of technology in modern education is undisputed, and it is now in focus in the light of the current developments and upheavals due to the pandemic. There have been some debates in higher education about how technology is integrated into the classrooms, but most commonly, it is both mixed-mode and distance-education delivery. This is differentiated when the course or program is being planned, the designing of the course, and how the students who are not on campus full-time are impacted (A. W. Bates \& Poole, 2003). To explain the delivery modes into the current context, mixed-mode delivery is where the traditional methods such as scaffolding, instructional, and collaborative pedagogies are adopted. This does not mean that there is no use of digital tools in this mode of delivery. Still, preferably, technology is used to aid an educator in ensuring the interactive presentation and sharing of the learning content rather than an educator being the old source of knowledge. Distance-education, which is certainly new to the $21^{\text {st }}$ century, can be defined as a phenomenon 
that "brings together the physically-distant learner(s) and the facilitator(s) of the learning activity around planned and structured learning experiences via various two or multi-way mediated media channels that allow interactions between/among learners, facilitators as well as between learners and educational resources" (Saykili, 2018, p. 5). It implies specifically on the physical separation of learners and facilitators of the learning activity. It is ensured that the learner is in the center of the learning experiences and takes more responsibility for their learning as independent learners (Saykili, 2018). Since technology is the carrier of information and illustrates the combination of information and technology (Büyükbaykal, 2014; Hamidi, Meshkat, Rezaee, \& Jafari, 2011), it allows educators and learners to communicate remotely.

Distance learning acts as a critical element in higher education. This is because students have access to different methods to acquire knowledge, and to a certain extent, it enhances the quality of students' learning. Distance education has always been mediated using technology so that its landscape has been redefined and reshaped by it. The more advanced features and newer affordances technologies acquire, the more possibilities and opportunities there are for distance education delivery. One such possibility was incorporating two-way communication systems such as audio/video conferencing and synchronous and asynchronous computer-mediated communication. This naturally instigated the idea and necessity for incorporating such interactive tools in distance education courses in the third generation (Anderson \& Simpson, 2012). Likewise, the impact of digital technologies with extended communication possibilities has anchored the importance of interaction even more. Through these technologies, a shift of focus has been inevitable from the organization and didactic teaching to the social construction of knowledge (Anderson \& Simpson, 2012). Hence, it is in line with social constructivist as well as connectivist theories of learning.

Both in Australia and other world countries, the 'times of crisis' have led to today's complex and virtual classroom dynamic. Outside of the pandemic context, navigating LMS decisively is a facet of digital literacy, a transferable skill amongst others, which has increased 212\% between 2014 and 2017 (Australians, 2017), making it an essential skill for 21st-century learners in Australia. The educators who were still supporting arguing the 'old glory' of the traditional delivery of education have faced a considerable change regarding incorporating modern digital tools at the university level during an unprecedented time of the pandemic. The closure of university facilities has modern technologies to be immediately tested, verified, and supported, with their compatibility and user-friendliness of their software ensured. The current technological ways of teaching have impacted the way educators deliver the learning outcomes and the way students learn. It has also impacted the quality of education that is now made accessible to millions of students by introducing online courses and online resources. As it goes for the researchers in this study, the university offers both cloud teaching and on-campus teaching modes. Although these students' cohort is under one unit, cloud students do not have access to on-campus lectures. In contrast, on-campus students have the privilege to have a face-to-face lecture with an educator to assist their needs where required.

The importance of social interaction in the educational experience has also been the center of attention (Garrison \& Cleveland-Innes, 2005). This is whether the learning mode is online or face-to-face (F2F). Technology can then be used to provide social interaction with peers and teachers through a form of 'collaboration.' That is where the possibility of extending social connections through platforms like Microsoft Teams, BB Collaborate, and discussion boards are considered (LMS). Even though this was not verified through an empirical study, it is worth noting that the use of those platforms emerged through the time of crisis with two weeks to train, learn, adapt, and 'make-use' of the platforms for educators, professors, and also, for the students. This transition was attempted to be as transparent and clearly instructed as possible. However, there were many confusions, adaptation issues, technical issues at educators', students', and the curriculum designers' end who had to adapt and modify the curriculum to an online delivery format. Digital tools or software have certainly become essential in the continuation of education alongside the pandemic lockdown. With the transition to distance learning or online learning for all sectors during this time, it is crucial to learn how students transitioned. Students are presumed to be aware of the current technology, and their adaptability to the various platforms at a university level is 'expected' to be an 'easy' task. With the transition to distance learning or online learning for all sectors, it is crucial to learn how students transitioned. Despite this being a recent transition in higher education, the 
authors were encouraged to observe and anecdote the experience to improve the subject's delivery online, eventually improving how the students prefer and understand. The research published on anecdotal narrative records mainly focuses on children's individual development in all aspects, including curriculum planning, delivering learning, enhancing communication, and documenting skills that the learners may need towards enhancement (C. C. Bates, Schenck, \& Hoover, 2019; McFarland, 2008)

The transition from F2F to online teaching, or rather distance learning, has its challenges and drawbacks. Reflection from students provides a thorough record of experience through their transition, and it is a well-established tool for learning. Therefore, this paper brings attention to how students' transition was established from F2F to distance learning. This includes what they feel about the transition, what types of challenges were encountered, and how this transition impacted their learning styles. Moreover, it is correlated with the researchers' experience as educators during the transitioning of the teaching mode to provide a perspective of students' learning abilities and teachers' compatibility to adapt, teach, and learn with digital tools; in this case, MS Teams, BB Collaborate, and discussion boards of the university's LMS (learning management system). The data used to present in this article depends solely on the authors' experiences as educators and reflection on what has been observed throughout the pandemic transformation. As anecdotal narrative records are gathered throughout pandemic time, the authors underpin this approach with a theoretical stance and qualitative thematic analysis of the records. It should be noted that factors that seemed to assist students via online/distance teaching are the way an educator's personality reflects the subject being taught and how accommodating the educator is, with providing an 'environment' where they can feel comfortable - despite it is not the same as F2F classroom.

\section{RELATED LITERATURE REVIEW}

This section provides the context of the types of digital tools (Microsoft Teams and University's LMS (BB Collaborate and Discussion boards) used in the undergraduate units and briefly explains their functionalities and features that aided the educators and students to communicate with each other.

\section{Microsoft Teams as a Learning Tool}

Microsoft (MS) Teams is a cloud application that acts as a shared workspace to allow fluent collaboration, communication, and sharing tasks between colleagues/groups with a secured learning experience. Although Teams have been popular in various industries such as the corporate world, it has made a breakthrough in education due to the current pandemic. MS Teams is equipped within Microsoft Office 365 for Education package, along with other software including Word, PowerPoint, OneNote, OneDrive, Outlook, Stream (drive), SharePoint, personal chat, interactives such a list of attendance can now be downloaded, which was initially not provided March 2020, uploaded files can be edited. Conversations can be specifically addressed to an individual to acquire an immediate response, dial-in with one click, and a shared screen can be requested to control others in the meeting to allow collaborative work at this current moment of use. The authors believe that the MS Teams have worked on reflective messaging through live reactions to show inclusivity and provide an engaging presentation. The interactive whiteboards, which existed initially, have now been removed due to approximately 800 million users reported in April 2020. This difference can be noticed in the report by Forrester on the projected economic impact where Teams are now offering up to 400+ applications available within the Teams store (Research, 2019). MS Teams is amongst the top three most used applications by high schools for online teaching and learning. MS Teams users are provided with additional classroom management features as an LMS. For instance, with 13 million daily users, Microsoft Teams overtook Slack in July 2019 (Forbes, 2019). Existing studies show that platforms like MS Teams can lead to better knowledge management (Wehner, Falk, \& Leist, 2017) or, more generally, to increased productivity (Kügler, Smolnik, \& Kane, 2015). Simultaneously, there is evidence that failure rates of collaboration platform initiatives are growing (Giermindl, Strich, \& Fiedler, 2017).

The authors used this platform for sixteen (16) hours a week for four months (March - June 2020), and it is still being used for delivering online lectures weekly. Teams are designed to empower their users with 
collaborative features such as sharing files, recording videos, saving through the Stream cloud, and allowing all team members to access resources in a fast manner (Research, 2019). MS Teams have been used in various fields where collaborative knowledge building is required between groups. A recent study reported, through a survey data collection, that MS Teams is valuable and reliable in terms of sharing essential documents collaborating authoring, allowing students to develop abilities during the sustainability assessment methods (Buchal \& Songsore, 2018). Another study examined the effects of using MS Teams to negotiate the scaffolding learning processes of solving complex problems, peer interaction, and learning performance through a collaborative learning environment with undergraduate students (Shin, Kim, \& Song, 2020). The authors compared the performances of different groups who had access to various LMS platforms. The results showed a positive impact on the use of MS Teams and an LMS based on the context.

\section{Learning Management Tool (LMS) - Blackboard Collaboration and Discussion Boards}

The Blackboard Collaboration and discussion boards are a part of the university's LMS; therefore, they will be discussed from the students' perspective. The discussion board for on-campus undergraduate students was barely active as the students would meet and discuss with the tutor during the sessions. However, with the transition, the F2F session turned into a BB Collaborate session, and discussion boards became highly active. Although these two interactives were limited with essential communication (no graphics), the LMS is poorly featured compared to MS Teams. A learning management system (LMS) is defined as an educational platform within institutions that offers an integrated platform to post, collaborate, and share teaching materials among teachers, learners, and the management of institutions (Thuseethan, Achchuthan, \& Kuhanesan, 2015). It has been used widely in higher education because it offers flexible learning times and unlimited distance education (Hamuy \& Galaz, 2010). BB Collaborate is used to share screen, deliver video lectures (recording feature available), chat live, have breakout rooms for group discussions, and allow students to share their screen during presentations on Cloud drive and limited to no graphic. Recently introduced editing/providing feedback using a word file editor tool; however, only some units have access to this feature. The user interface is simple and allows navigation around the site to be simple. The lecturers create discussion boards, and it provides students with a space to ask questions after lecture hours or share thoughts about the unit. It allows push notifications to keep track of updates for all courses, and you can customize to enable email notifications. This paper does not cover the assessment submission details of LMS.

\section{Comparison Between the Platforms}

The comparison between MS Teams and LMS is distinctive in its unique manner. Personally, MS Teams was not built for educational purposes; however, it has evolved rapidly to adapt to education rapidly. LMS has also recently made changes to provide more functionality, such as editing tools and breakout grouping for private discussions of separate students' groups. However, there are still certain drawbacks that can be faced by both educators and students while using both tools for the first time. MS Teams is commercial software, and although offering Microsoft 365 for education, it is a comprehensive digital tool to be purchased on its own. As Australia primarily accommodates international students, it is crucial to address that adapting to digital devices is not 'desirable' as they enroll as on-campus students. LMS accessibility can take time to adjust; however, Teams is accessible on any device (PC, Tablet, Mobile). As a personal experience, students were able to dial into the session immediately. Although MS Teams requires an initial training session for educators to undertake, it seemed more reliable, easily manageable, and highly interactive - which engages the students, promotes participation, and is highly engaging throughout the sessions

One typical drawback of the LMS is that information can only be transmitted unidirectionally from the educator. Moreover, during the BB Collaborate session, the students' interactions in the classroom may be overlooked and interrupted due to internet connections, so hardware issues for students (Mic or speakers do not function), hence, demotivate the students to join the session. On the contrary, MS Teams provides all the necessary interactive features, but it is also designed to create a teaching and learning environment using the foundation of Office 365 tools. Also, LMS users are usually unable to share their work or 
cooperate on the same file; hence, using other tools like Dropbox and Google Drive. This delays the productivity between students and demonstrates a lack of engagement. Lastly, MS Teams is integrated with new technologies like a bot, artificial intelligence, auto tools, etc., which possess great developing potential in the educational sector.

\section{METHODOLOGY}

A brief explanation of the theory used in this study and the data analysis method is presented in the following sections.

\section{Theoretical Framework}

The theoretical framework used in this study is adopted from the 'Experiential Learning Theory' presented by Kolb (D Kolb, 1984). From an epistemological perspective, the researchers believe that learning occurs once we, as educators, accept the conscious and subjective aspects of learning. Accordingly, we believe that in every experience-based learning process, not only is it not sufficient to 'do' and 'think,' but also there must be a link between doing and thinking. It can be claimed that experiential learning theory is, in its essence, different from previous predominant learning theories such as cognitive learning theory and behavioral learning theories. Contrary to the latter two theories, experiential learning moves away from abstract acquisition and manipulation of information and welcomes the role of consciousness and subjectivity in the learning process. Through the experiential learning model, learning can be defined as: "... the process whereby knowledge is created through the transformation of experience" (David Kolb, 2015). Through this definition, several vital factors stand out. The first point is that learning is considered a process rather than an outcome. Second, knowledge has a fluid nature, which is being continuously created and recreated. Third, learning through experience encompasses both objective and subjective forms. Moreover, we need to understand learning; we, as educators, need to understand knowledge. Our ontology defines our epistemology, which, in turn, explains how we believe learning takes place and what we expect from our students.

To better understand the link between experience and learning, or in other words, between doing and thinking, Kolb presented his model of experiential learning in a cyclical form, Figure 1. As shown in Figure 1 , the model is presented cyclically, advocating that once learners complete one cycle, we can claim that learning has happened. The critical issue here is that this allows educators and teachers to create and design their material to fit each stage of the cycle to achieve the most efficient teaching/learning outcome.

\section{FIGURE 1}

\section{KOLB'S EXPERIENTIAL LEARNING MODEL (1984)}

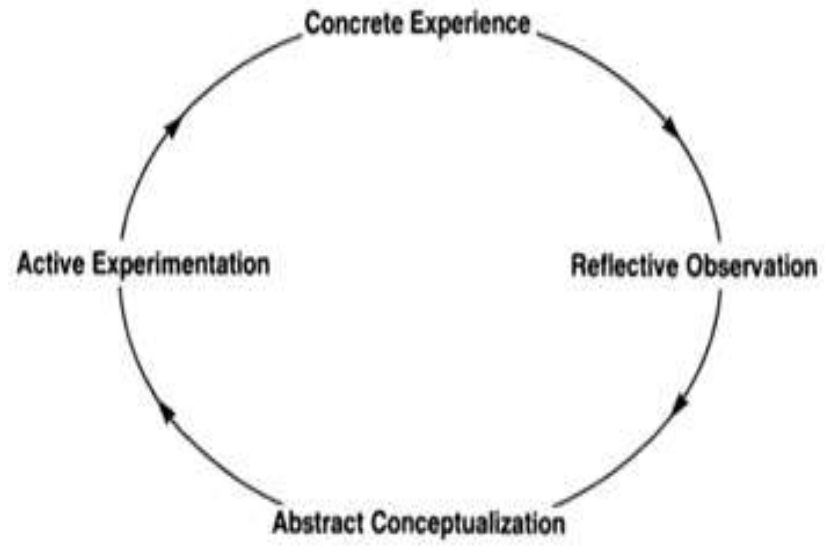


However, literature does provide some criticism of this learning model. For instance, it is believed that this model is somewhat deterministic and narrowed in its nature in that learning cannot be considered a sequential, ordered-steps process (Forrest, 2004); or that this model does not take into account the social, historical, and cultural aspects of learning (Beard \& Wilson, 2006). Furthermore, after applying this model to assess students' learning styles, it is claimed that it can provide a rich environment for 'deep learning' (Wyrick \& Hilsen, 2002). However, 'deep learning' has only been defined as recalling details over a long period. Certainly, Kolb's model goes beyond a simple 'recall' of information, as it encompasses both abstract reasoning and reflective observation. Table 1 presents the four stages of learning in Kolb's Experiential Learning Model.

TABLE 1

KOLB'S LEARNING MODEL STAGES AND DEFINITIONS ADAPTED (1984)

\begin{tabular}{l|l|l}
\hline$\#$ & \multicolumn{2}{|c}{ Kolb's Experiential Model (1984) } \\
\hline 1. & $\begin{array}{l}\text { Concrete experience (CE) } \\
\text { (such as observations, laboratories, } \\
\text { primary text reading, problem-solving) }\end{array}$ & $\begin{array}{l}\text { The learner makes observations and reflects on them. } \\
\text { It is the input of information either from experience or } \\
\text { from abstraction. }\end{array}$ \\
\hline 2. & $\begin{array}{l}\text { Reflective observation (RO) } \\
\text { (such as discussion, brainstorming, } \\
\text { thought questions, rhetorical questions) }\end{array}$ & $\begin{array}{l}\text { On the basis of reflection, the learner draws out logical } \\
\text { conclusions and makes generalizations. }\end{array}$ \\
\hline 3. & $\begin{array}{l}\text { Abstract conceptualization (AC) } \\
\text { (lectures, paper, projects, assessments) }\end{array}$ & $\begin{array}{l}\text { Based on their generalization, they gain new } \\
\text { knowledge that can be applied in other scenarios. } \\
\text { Hence, the logical conclusions are added alongside } \\
\text { their constructs of learning. }\end{array}$ \\
\hline 4. & $\begin{array}{l}\text { Active experimentation (AE) } \\
\text { (case studies, fieldwork, simulations, } \\
\text { group projects) }\end{array}$ & $\begin{array}{l}\text { The learner tests these generalizations and hypotheses } \\
\text { through experimentations and further experiences. } \\
\text { The conclusions and constructs created previously } \\
\text { guide decisions and actions that lead to new concrete } \\
\text { experiences. }\end{array}$ \\
\hline
\end{tabular}

\section{Data Analysis}

The narrative, anecdotal records (Beaty, 1994) are descriptive forms of narrative that can be documented after observing a specific behavior or interaction that occurs through the classroom. This is based on the F2F classroom setting. However, as an educator who has gone through the change alongside students, it provided an approach to visualize, observe, and compare the differences. The educator recorded the records every week while the teaching sessions commenced through the trimester. When the educator observed a drastic response and clarified through the student, the observed event was audio recorded with the time-stamp. This gathered up to 36 anecdotal experiences, where valuable and highly crucial aspects of the change in learning modes were witnessed. In addition, the audio recording as one method of data collection in the anecdotal approach (observational data) has been proven to be valuable (McFarland, 2008). Having descriptive narrative recorded to visualize the change in the adaptability of students, technological issues and the challenges they have faced, their way of requiring feedback or opinions, learning progress, and the impact of 'the need' of feedback for students to affirm on the process of getting a better grade.

The records were transcribed and analyzed thematically through emerging nodes, themes, or recurring ideas discussed and observed throughout the recordings. This approach to data collection did not require distress to students during tough times. The records may be time-consuming, but they provide a more naturalistic approach and meaningful information on students' perspectives. The themes were then analyzed using the hermeneutic interpretivism paradigm. Furthermore, it aligns the researchers' epistemological and 
ontological stance with Kolb's experiential learning model and Heidegger's idea of hermeneutics. The distinction between the individual and the experience is erased, and the interpretation stems from a coconstitution of the two (Laverty, 2003). The researchers' understanding of the themes was based on the hermeneutic circle, which constitutes reading, reflective writing, and interpretation (Laverty, 2003).

Lastly, as an educator with over eight years (combined 8 to 10 years for both authors) of teaching F2F and distance mode, the transition of change in learning and teaching mode has changed rather drastically due to Covid-19. Therefore, anecdotal records and experience as an educator may shed light on some crucial aspects of teaching undergraduate students regarding engagement and motivation.

\title{
RESULTS DISCUSSION: THEMATIC ANALYSIS OF ANECDOTAL RECORDS
}

This section discusses the six main themes discussed with some anecdotal narrative comments. The results are discussed and interpreted through the theoretical stance of the educator. To contextualize, some quotes are presented to demonstrate what students expressed during the sessions. All names are acronyms and deidentified to maintain anonymity. With data analysis achieved through NVIVO, common themes were emerging and categorized into six main themes. The discussion of the main themes is addressed alongside using a specific digital tool and the students' experience. Consequently, each theme is concluded with the researchers' experience and reflection towards the theme's discussion.

\section{Theme 1: Challenges Encountered During the Learning Mode Transition Subtheme: Adaptability of Digital Tools by Students}

This theme emerged through students who had used MS Teams and the LMS, including BB Collaborate and discussion boards. It was simply observed that the students struggled with using digital tools and using them to engage with the educator. Sometimes, educators have to wait a few minutes before beginning the session to ensure everyone can hear, speak and see the shared screen. There were two sub-themes derived, and they are interpreted below. Due to the limitation of the length of the paper, the students' quotes are presented limitedly.

\section{Technical Issues to adapting the digital tools.}

Most of the students seemed to be confused about operating around the digital tools for a starter. They appeared to show their concerns through the confusion and doubt of what is right and wrong to do. The students would join in the session, the microphone is either connected or faulty, and the video would be switched on or remain off. The students' perspective shared below suggested the inconvenience by presenting a vital point: "Student is typing...". This interaction does not exist in both BB Collaborate and MS Teams. Perhaps, providing an interactive to allow educators to realize that a student is typing can assure educators that even though they are silent, they are typing the answers or communicating.

\begin{abstract}
[Maryam]: “... Sometimes my laptop speaker or Mic will not work, and I could not answer the questions as quickly. Also, it made it hard for lecturers and tutors when they ask questions, and they think no one will answer or hear them because of no feature that says "student is typing."
\end{abstract}

[Arora]: "...It was also hard to be able to ask questions in the class, some questions posted in the chats were either not acknowledged, or they interrupted the flow of the class, and the class felt disjointed."

\section{Transitioning from Face to Face to Online (Distance Learning)}

There was barely any positive comment from students that online learning made it convenient for their learning routines. Except for one student from the IT faculty, who seemed to enjoy online lectures, their way of communicating through digital tools seemed easy; however, they did seem to raise doubts about what their educator is questioning or expecting from them. 
[John]: "As an IT student, I would say learning online was great, but in some cases, like if I did not understand what the unit chair wants us to do, it was a bit messed up, I would say because I am used to getting answers for my questions by physically/face to face attending a class...."

Many students 'uneasy feeling' expressed 'asking a question without interruption' was quite interesting. If the question is written, how will it be acknowledged, or 'should I speak?' The students seemed to be unable to communicate with the educator. As an educator, it is tough to have an undergraduate student participate during a F2F session. Concerning how students have displayed their discomfort towards online learning, educators ask questions, pause to observe if there is a question, or if any student has discovered the button "to raise hand" virtually to capture the educator's attention.

[Sam]: “... Online lectures are hard to focus on... It is hard to get a sense of how much or how little work you have done without speaking to your classmates..."

[Amin]: “... being an on-campus student, it was challenging for me to cope up with the online learning in the beginning. All of my lectures were pre-recorded, and there were no Live classes... that is not what I am used to, and I could not focus because it felt like a podcast... one-way information.."

Another common term used was 'distraction.' The students seemed to relate online recorded lectures with the term 'distracting' or becoming demotivated to continue with the video online. They also avoided the use of video cameras being used in the live lectures. They only just need to 'hear' the lecture and be present to get attendance done - as observed.

[Connor]: “... Quite hard because I can be easily distracted and feel lazy to some parts during the session... if I am at home in my environment... What we used for lectures was okay, but rather in-person interactions would essentially help me not get distracted..."

[Scarlett]: "However, a downside to lectures and seminars utilizing digital tools introduced many potential distractions such as YouTube and other sites that were not Uni related."

As an educator, the interaction during the live session of the lecture was crucial. The use of animation, creating PowerPoint slides with engaging infographics, allowing creativity through visual graphics and audio/videos to be played through the interface to ensure the students did the same at their end when a task was given. This allowed students to engage with the same resource material to discuss students and educators effectively.

\section{Theme 2: Making Learning Engaging and Motivational}

For F2F students, the lectures are engaging as an educator is physically present towards whom they can empathize, connect, communicate, and 'feel' the presence in space - the classroom. For online students, it seemed to have completely transformed their opinions about lectures. This affected their motivation to learn, attend a lecture, participate during the session, and engage actively through an online session. Some units had pre-recorded lecture sessions to allow students to learn at their pace. As educators, we understood that not every student could have a stable internet connection. We established that self-paced learning could occur due to the availability of resources. However, the students seemed to disagree and leaned towards poor learning habits instilling lazy learning attitudes, procrastination, or not keeping themselves up to date with the new posts on their units. Consequently, this turned into emails and queries at non-working hours 
and late submissions, which required extensions as flexibility was the most vital point at the "challenging time' for everyone. The engagement between an educator and student may be increased if some rules are set for students, but, personally, if the students were not provided with feedback as soon as possible, there seemed to be a 'panic' for students, and misunderstandings seemed to be very common.

Even though the lectures were recorded, they did not seem to be an engaging experience for them. Some positive responses demonstrate the intended purpose of the recorded lecture - 'listen anytime and as many times as required.'

[Parker]: “...After few weeks, I got adapted to online learning. I have not enjoyed the classes that much, but it seemed okay for the current situation. Because watching the recorded lectures did not look engaging at all. I tried to submit my work promptly and received good comments from the faculty..."

[Jess]: “... Compared to seminars being delivered in person, the use of other digital tools had its ups and downs. The good thing about watching lectures/seminars online meant you could re-watch them over and over again and do so at your own pace. It also allowed me to come back to the lesson another time in case I was feeling overwhelmed..."

It was interesting to visualize the use of MS Teams as a Chat Messenger to contact the educators whenever they required details on the unit/course. It may seem as though it is a higher level of conversation or communication between the peers; it may be discomforting, causing inevitable distress. As an educator, the first author recalls being 'alarmed' at all times to ensure that the students' well-being was well-attended. Although this is not enforced upon us, it became ordinary for the distance learning process.

[Jesper]: "Main challenge was that I lost my motivation for most of my work and deadlines. I could not stay on track. I kept putting things off to the last possible minute..."

[Ella]: "It is hard to get a sense of how much or how little work you have done without speaking to your classmates. It is hard to listen without eye contact when people are sharing their slides. I also miss all the social cues, so it is hard to tell if people are joking or asking questions, and you cannot play off people's ideas because you cannot read their reactions."

\section{Theme 3: Students' Preferences on the 'Type of Learning Mode'}

It was fairly interesting to notice how frequent students mentioned, "I miss F2F classes..." or "I just cannot seem to manage time and keep updated...". As the condition of remaining online learning continues, it is crucial to gain students' perspectives that would better deliver teaching online.

With the analysis of all anecdotal records, none of the students preferred online or distance learning. They objected to the idea of being online and demonstrated rejection towards how the process of learning is achieved. Some students acknowledged that the transition occurred due to the pandemic but primarily referred to the transition as 'negative' towards group discussion and reduced social interactions. Additionally, including physical presentation of work and support, awkward silences during the online sessions, reduced direct engagement with the educator, and disappointment toward not sharing one's group project or work. Moreover, some students who preferred online classes positively impacted students' personal preferences who acquire knowledge better in a classroom environment and allow themselves to participate during F2F actively.

[Susan]: “... I personally prefer face-to-face learn over digital because I find myself getting into a much better headspace when I am in a classroom surrounded by other students..."

[Nareem]: “... I miss Face to face, I would learn a lot better as a personal preference...” 
[Kela]: "I still recall how engaged I was in Face to face because I listen better when I am in a class environment where there are no temptations or distractions are going on with my phone and even zoning out."

[Anna]: “... In online classes, the breakout rooms created have different participants every single time, and because of this, the first ten minutes go into introducing each other and trying to ensure nobody is cutting the other person. Another disadvantage of online learning is that because we cannot see each other, other group members refrain from interacting completely..."

As educators, keeping students engaged requires much self-discipline to keep the motivation high, provide a casual and approachable attitude to ensure the students feel comfortable, and ensure they are focused. Distance learning becomes questionable when 'distraction' becomes more prominent and social platforms or gaming applications exist on the same computer. To allow a more disciplined learning session, the educator must guide the students, give a specific time for each task, and enable them to return or, perhaps, begin the session to allow them to return to the session. This helped to maintain a safe time for them to learn and reflect.

\section{Theme 4: Students' Suggestions on 'Making Learning Process Better' During Pandemic}

Sometimes, students felt the need to share what could make the learning better through distance learning because, as educators, they always seemed to compare their experience from F2F. There was a repetition of the platforms' types to be used for all units through the analysis. The students preferred lectures to be 'live' and accessible, replace examinations with more assignments, the duration of seminars to be shorter, resources shared for all students (cloud and online/distance learning mode students). Moreover, encouraging students to 'switch their cameras on' to replicate 'classroom environment,' students complimented educators' enthusiasm, making the sessions fun and challenging. The idea of group assignments was highly rejected due to online teaching, and no social interactions between students were achieved through an online lecture compared to F2F. The feedback from the educator was highly demanded. These reasons were summarized based on how the students suggested ideas and improvements.

[Shane]: “...I would probably suggest that there is a need to have consistency for the platform we are using for our classes, like some a teams, some a zoom some are BB collaborate... groups created in the seminars should remain consistent, at least for that specific seminar... and the tutors and lecturers should allow some time at the end of the seminar and lecture for questions OR keep regular question-answer sessions...."

[Veera]: “...Affected by the epidemic situation; the completion of the group's work is severely affected... I do not progress and focus much anymore."

[Aruba]: “... No online learning, please. I would suggest for future online classes that all students are mandatory to be on video to replicate a classroom environment."

[IIli]: “... Shorter seminars. Time at the start of class for a bit of chat that is not related to university work. More time to let students share their own screens with the class to show everyone what they have been up to."

We believe that the suggestions may ease the way students learn. However, they require a revision to be made by curriculum designers, learning outcomes of a unit, and how the shift between 'open teaching' or the open-source teaching' develops. This seems as though the educators should share the best teaching practice and disseminate their understanding of various resources to achieve the expectations freely and openly. An educator is expected to learn quickly, adapt to new tools, and effectively apply the knowledge 
to students. For this reason, various selection of platforms is selected to ensure the learning outcomes are delivered precisely and the perception of students being aware of technology use. They are provided with videos, guidance, and services to accommodate their technical queries. Despite the abrupt change, the students' attendance reduced over 11 weeks, gradually, and it demotivates the educator's enthusiasm; however, the 'time of crisis' has affected every individual in education institutions.

\section{Theme 5: The Impact on 'Feedback'}

Another emerging theme that we encountered was how feedback was provided to the students. During the live sessions of Zoom, MS Teams, or BB Collaborate, the way the feedback is given varies entirely to how students communicate through platforms. Because F2F allows a 'visual aid' for students to see the lecturer and approach to obtain some feedback regarding what they feel about the progress or what they understand from the lecturer's discussion during the classroom, this changed drastically. The idea that Online/Distance learning with students may be normalized is quite disturbing. The majority of the students hesitate to question the tutor, do not feel comfortable asking questions, and do not like to communicate their thoughts. With the way they want to communicate, it requires constant 'emails.' It has become quite common over the past 11 months (March 2020 to February 2021) that the students would instead email the lecturer to get feedback or opinion on their learning progress rather than asking during the live online session. Some students tend to quote in their emails, "sorry to bother you, I was hesitant to ask you this question while we had the online session, but I thought it is better to ask you personally instead." This has its pros and cons for the matter of 'consultation.' Imagine if you have 140 students per trimester to coordinate teaching and marking with; what if all the students or perhaps, majority of students decide to communicate through emails? As experiencing this ourselves, we as educators need to inform, correct, guide, and assist the students in need of help. However, this leads to exhaustion, time consumption, fatigue, and unappreciation for the efforts. However, this concerns the educators only to a certain extent; we strive to provide the best feedback possible. It works both ways: the students are presumed to read the provided content, guidelines, and instructions. The educator is present to ensure they have understood what is required for assessment or task or activities to be completed.

It is highly observed during this period of the pandemic that the number of emails increased tremendously. This includes feedback, unclarity of understanding the task to be completed, the progress of students' learning and achievement, and more effort from educators than ever before. This is argumentative with motivational and engagement aspects that are overlooked and ignored. We realized that the need for students to receive a response was one of the motivational drivers of their learning. When they do not receive detailed feedback or an email response, they seem to lose motivation quickly. Some students respond through emails, "thank you so much for appreciating my work! I will fix all the designs as directed! I put much effort! I am so happy you liked my work!". This is relatively uncommon to experience during F2F lectures. Some students prefer F2F because they can get feedback from peers on a project they are working on and feel more involved. Some anecdotal quotes from students over time sharing their thoughts about how they felt feedback impacted their learning progress.

\section{[Jackson]: “... I just think that the ability to ask questions and answers from the unit lecturer is so less now... I am afraid to interrupt, and I sometimes do not know silly my question may be... I want discussions posted on the boards, which helps overcome any doubts and concerns, but sometimes there is no interaction for sometimes, so I get demotivated about it...."}

For example, in those disciplines that use lecture and midterm and final exams, mechanisms for faculty contact and feedback may be reduced (often as a result of the related issue of class size). Students' confidence in their abilities or in their expectations for success may also suffer. The relevance and meaning, and value of the content may not be as apparent because of limited opportunities to become aware of or to truly understand course goals. Student involvement in and ownership of the responsibility for learning are reduced even though the situation seems to be one in which this responsibility is left to students. 
The difference, of course, is that simply leaving students to "sink or swim" does little to support their acceptance of responsibility or the development of the expectation that their efforts will result in success.

[Susan]: “... I would really want F2F classes because I am never able to show your work to others and gather feedback on it!... it really hurts the work. The online class is too formal. You cannot chat with the people next to you before, after, or during work. You have to do your work in isolation and hope it is good with only having the teacher for feedback when it is online. Moreover, the student-teacher formal relationship can slow this all down and make it very serious...."

\section{Theme 6: Mental Health of Students and Their Expressions}

Another theme related to the pandemic occurrence and the students' personal life changes was quite often brought to attention. The students' mental health - where COVID-19 had dismantled their work routines as many individuals lost their jobs, some students would get overwhelmed and email the educators for extensions, unable to focus, unable to understand instruction, cannot access because they have inadequate internet facilities, etc. As educators, we are directed to accommodate and guide them for their betterment and support them through other services provided for students' care if specific issues are severe. This became very common. Many students explained their situation through emails to inform lecturers of their assessment progress. Their work routines have altered that do not allow them to join in live lectures, or the assessment is unclear, leading to learning progress. Therefore, they require more time to complete the task. Observing this drastic change also impacted the mental health of educators/lecturers. The sudden change, the adaptation, and ensuring the facilities were present, guiding students with the basic instructions to be online and present for any ongoing issues at the student's side. Some students would express how they dealt with the change and pandemic affecting their lives. One student mentioned that "I have been trying to adapt to a new environment; I found it was putting a strain on my mental health, as I struggled to think properly and focus on my work. Upon being moved to online learning, I found that over the first Trimester, my performance across some of my units was not as good, compared to if I was in the classroom...". This is a sensitive issue; therefore, I would like not further explain its impact on students' progress - where many students, without proper support, empathy and sympathy, had dropped out of the course due to their stress or anxiety levels. Some of the anecdotal narrative records are presented below:

[Joshua]: “... sigh... Mentally, it did have an effect on me with the learning being online. I am a person who would learn better in a classroom environment, being out of the 'being at home feel."

[Sarah]: “...trying to adapt to a new environment is difficult... I found it was putting a strain on my mental health, as I struggled to think properly and focus on my work... there are too many distractions at home, and other family members have their own needs of internet ..."

[Gemma]: "... I really wish to have the direct communication with my Lecturers which I had previously. I faced anxiety and procrastination throughout the online learning with all of my assessment work... I just left it for the last moment of submission..."

[Anthony]: “... to be honest, I prefer face-to-face classes to get more assured feedback... if it were not for you, I would have lost track of time and interest in this unit... you always guided me and answered immediately to help me... It helped reduced my stress a little...."

As educators, the experience we gain throughout the years to learn, accommodate students, ensure they learn, provide guidelines, and be a 'role model' for them. The pandemic change has been challenging for all educators and students. The difficulties that impacted the education systems, emphasizing developing 
higher-order thinking and problem-solving skills through distance learning, are nearly impossible. The information apocalypse era and the reach of information at our fingertips have both strengths and weaknesses. Higher education teaching and learning is processing information and memory retention of the human brain, and the emphasis of higher education curriculum has shifted to 'thinking' instead of just 'learning (Gagne, 1980). Lastly, this paper's anecdotal approach is an eye-opener, as the higher education published work does not value the approach. It is mainly applied to teachers in primary and nursery levels of children. The authors attempted to apply the approach to higher education students. We believed that there is a need to publish anecdotal narrative records for students 'freely' speaking about their opinions and allowing researchers to comprehend its crucial value.

The authors attempt to conceptualize an instructional sequence of F2F learning and distance learning based on data analysis and interpretation. This is achieved by adapting Kolb's model. Figure 3 shows that concrete experience represents the F2F classroom context, and abstract experience is distance learning. The activities are generalized to provide an overall idea of how F2F and distance learning activities are achieved. This can potentially enhance specific disciplines or courses for future references.

\section{FIGURE 3 \\ PROPOSED CONCEPTUAL LEARNING MODELS BASED ON KOLB'S EXPERIENTIAL LEARNING MODEL}

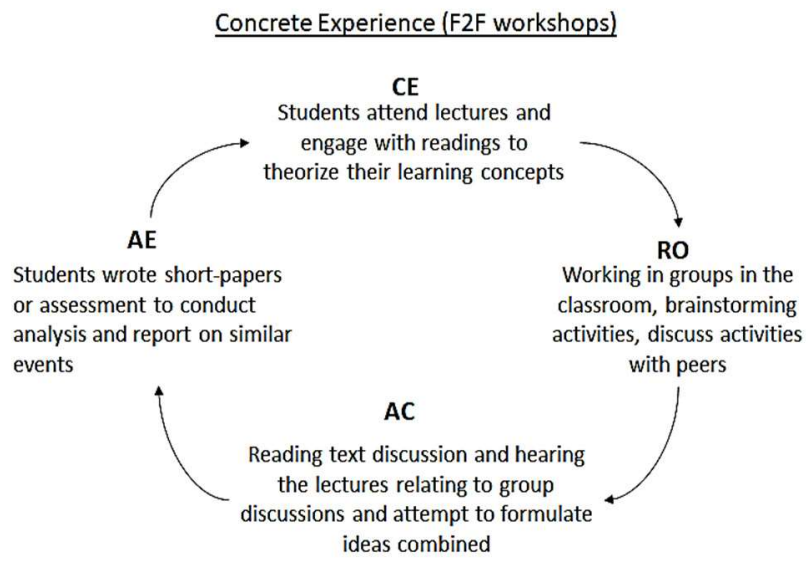

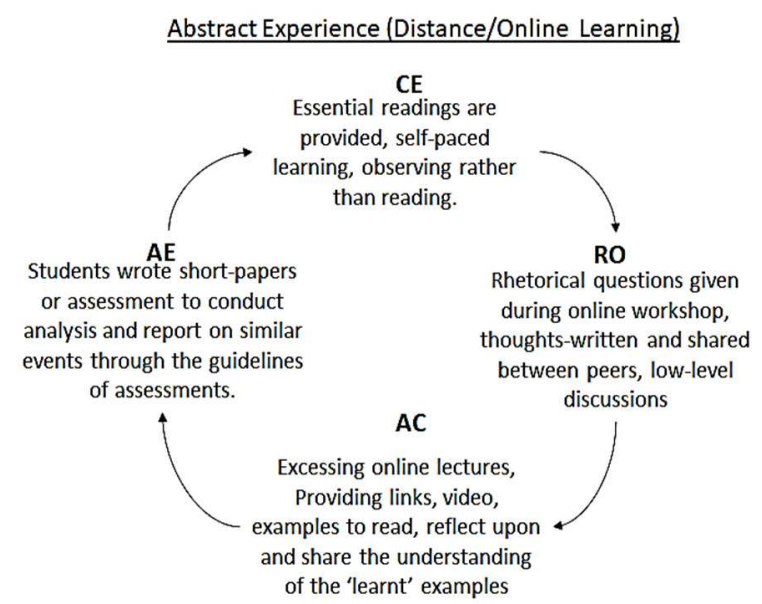

\section{CONCLUSION}

This paper addresses the challenges and perspectives encountered by undergraduate students during the transition of F2F to distance learning. The sudden change made 'acquiring learning' different for every student. An anecdotal narrative approach to understanding educator's experience and their reflection on how students' perspectives are observed were crucial to explore. This paper discusses the way students adapted to the digital tools (MS Teams and BB Collaborate), how learning could be made engaging and motivating, the impact of the transition to the communication between educator and student, and their preferences to the type of learning mode. Lastly, their suggestions to allow a better learning process during the 'change.' Educators attempt their best to achieve an engaging session. However, despite the difficulties and challenges in the students' technical and engagement levels, there were some positive discussions on using animation, allowing more time to students, reducing session times, and replacing examinations with more challenging assignments. The effects on collaborative work seemed to work partially through the students. This may enable us to consider creating a safe collaboration space where the ideas can be discussed openly and critiqued through a critical thinking process and scaffolded to its requirements. Kolb's experiential learning process is conceptualized to present two different learning processes that occurred as the transition began after the trimester commenced. Despite the initial response recorded in this paper, the 
students seem to adapt well to MS Teams and their functionalities after seven months of the pandemic. As authors and educators of this paper, we believe that students require a longer time adjusting, accessing, understanding, and becoming confident with the technologies used.

\section{REFERENCES}

Anderson, B., \& Simpson, M. (2012). History and heritage in distance education. Journal of Open, Flexible, and Distance Learning, 16(2), 1-10.

Australians, F.F.Y. (2017). The new basics: Big data reveals the skills young people need for the new work order.

Bates, A.W., \& Poole, G. (2003). Effective Teaching with Technology in Higher Education: Foundations for Success. San Francisco: Jossey-Bass.

Bates, C.C., Schenck, S.M., \& Hoover, H.J. (2019). Anecdotal records: Practical strategies for taking meaningful notes. YC Young Children, 74(3), 14-19.

Beard, C., \& Wilson, J.P. (2006). Experiential Learning: A Best Practice Handbook for Educators and Trainers. Kogan Page.

Beaty, J.J. (1994). Observing development of the young child (Merrill 3rd edition). New York.

Buchal, R., \& Songsore, E. (2018). Collaborative knowledge building using microsoft sharepoint. In Proceedings of Canadian Engineering Education Association.

Büyükbaykal, C.I. (2014). Communication technologies and education in the information. Procedia Social and Behavioral Sceinces, 174(2015), 636-640.

Forbes. (2019). Microsoft Teams Hits 13 Million Users To Tighten Grip On Slack. Retrieved from https://www.forbes.com/sites/adrianbridgwater/\%202019/07/12/microsoft-teams-hits-13-millionusers-to-tighten-grip-on-slack/

Forrest, C. (2004). Kolb's Learning Cycle. In Fenman's Train the trainer series.

Gagne, R.M. (1980). Is educational technology in phase? Educational Technology, 20(2), 7-14.

Garrison, R., \& Cleveland-Innes, M. (2005). Facilitating cognitive presence in online learning: Interaction is not enough. The American Journal of Distance Education, 19(3), 133-148.

Giermindl, L., Strich, F., \& Fiedler, M. (2017). Why do you NOT use the Enterprise Social Network? Analyzing Non-Users' reasons through the lens of Affordances. Paper presented at the Proceedings of the 38th International Conference on Information Systems, Seoul, South Korea.

Hamidi, F., Meshkat, M., Rezaee, M., \& Jafari, M. (2011). Information Technology in Education. Procedia Computer Science, 3, 369-373.

Hamuy, E., \& Galaz, M. (2010). Information versus communication in course management system participation. Computers \& Education, 54(1), 169-177.

Kolb, D. (1984). Experiential Learning: Experience as the Source of Learning and Development. New Jersey: Prentice Hall.

Kolb, D. (2015). Experiential Learning: Experience as the Source of Learning and Development (2nd ed.). New Jersey: Pearson Education.

Kügler, M., Smolnik, S., \& Kane, G. (2015). What's in IT for employees? Understanding the relationship between use and performance in enterprise social software. Journal of Strategic Information Systems, 24(2), 90-112.

Laverty, S.M. (2003). Hermeneutic phenomenology and phenomenology: A comparison of historical and methodological considerations. International Journal of Qualitative Methods, 2(3), 21-35.

McFarland, L. (2008). Anecdotal records: Valuable tools for assessing young children's development. Dimensions of Early Childhood, 36(1), 31.

Research, F. (2019). The Total Economic Impact ${ }^{\mathrm{TM}}$ Of Microsoft Teams. Retrieved from https://www.microsoft.com/en-us/microsoft-365/blog/wp-content/uploads/sites/2/2019/04/TotalEconomic-Impact-Microsoft-Teams.pdf

Saykili, A. (2018). Distance education: Definitions, generations, key concepts and future directions. Journal of Contemporary Educational Research, 5(1), 2-17. 
Shin, Y., Kim, D., \& Song, D. (2020). Types and timing of scaffolding to promote meaningful peer interaction and increase learning performance in computer-supported collaborative learning environments. Journal of Educational Computing Research, 58(640-661), 640.

Thuseethan, S., Achchuthan, S., \& Kuhanesan, S. (2015). Usability Evaluation of Learning Management Systems in Sri Lankan Universities. Global Journal of Computer Science and Technology, 15(1), $1-12$.

Wehner, B., Falk, T., \& Leist, S. (2017). What benefits do they bring? A case study analysis on Enterprise Social Networks. Paper presented at the 25th European Conference on Information Systems, ECIS, Guimarães.

Wyrick, D.A., \& Hilsen, L. (2002). Using Kolb's cycle to round-out learning. Paper presented at the American Society for Engineering Education and Annual Conference \& Exposition. American Society for Engineering Education. 